\title{
Architectural Conservation and Cultural Inclusion. The Applicative Case of Motta San Giovanni (Reggio Calabria-Italy) and its Romanian Community.
}

\author{
Alessia Bianco ${ }^{1, a}$, Vincenza Triolo ${ }^{1, b}$ \\ ${ }^{1}$ Mediterranea University of Reggio Calabria, via Melissari n. 189100 Reggio Calabria-Italy \\ aalessia.bianco@unirc.it, benzatriolo@tiscali.it
}

Keywords: Preservation, Emigration, Motta San Giovanni, Italy.

\begin{abstract}
The paper describes a restoration and reuse proposal for the Praci neighborhood in Motta San Giovanni, an inland town of the Reggio Calabria Province-Italy, aimed to accommodate and facilitate the integration of its migrant Romanian community. The project proposes a plan of self-constructive restoration, to be used as the residence of Romanian migrants, that for the Municipality could be a tool to make the whole community responsible for management and conservation of now abandoned a vernacular building heritage and for the migrant community could constitute not only an opportunity for improving its living, as well as social, condition, but also for taking advantage of a educative experience, considering that a significant part of Romanian migrants in Motta San Giovanni is employed in construction [1].
\end{abstract}

\section{Introduction}

In the contemporary Western culture a site or an architecture becomes cultural heritage, when we are able to see it as the result of a cultural, social and anthropic stratification; for this reason an architectural heritage is in itself expression of two conflicting, but at same time integrated, elements: a historical place survives and crosses ages and cultures if it has capability to change, to adapt; but this process is virtuous if it serves its identity, its genius loci. The mixture of these two trends is possible only if there is a set of circumstances, which constitute the elective affinities of a place. Analyzing and understanding these affinities is a necessary step in conservation, because often an recognition of these so shifting and intangible issues is basis for a proper conservation. The paper should show an applicative case of an architectural conservative proposal, where preserving the elective affinities of a place can mean transforming conflict and mistrust between different cultures in coexistence and mutuality.

\section{The context}

The geographical location of Italy and especially of Southern Italy made this country traditionally a place to access to Europe, both as a passage land as destination of migration. This process, which still happens today and sometimes with dramatic dynamics, over time had a very uneven trend, alternating periods with low flow and generally with good acceptance and periods with intensification of the migration process, determining a restriction of reception strategies. One of the most obvious consequences of these alternations is an evolution of local architecture or human settlements, characterized, especially in Southern Italy, by an extreme urban fragmentation, alternating sudden urbanizations to long periods of depopulation.

\section{The proposal}

One of the areas in the Southern of Italy where this process is particularly evident is Calabria, the most Southern region of peninsular Italy, which therefore is particularly interested by migration from Mediterranean countries, producing a multicultural and interesting anthropic and architectonic 
heritage, which is expression of an ancient integration between local communities and Albanians, Greek and Romanian migrants, who not rarely are victims of a prejudice, that confuses poverty with incivility [2]. An ancient villages that today well expresses this contrast is Motta San Giovanni (Fig. 1), which in the last fifty years has seen a gradual process of alternate phases of depopulation, caused by the abandonment by the local community [3], and phases of repopulation, thanks to coming of foreign communities [4].
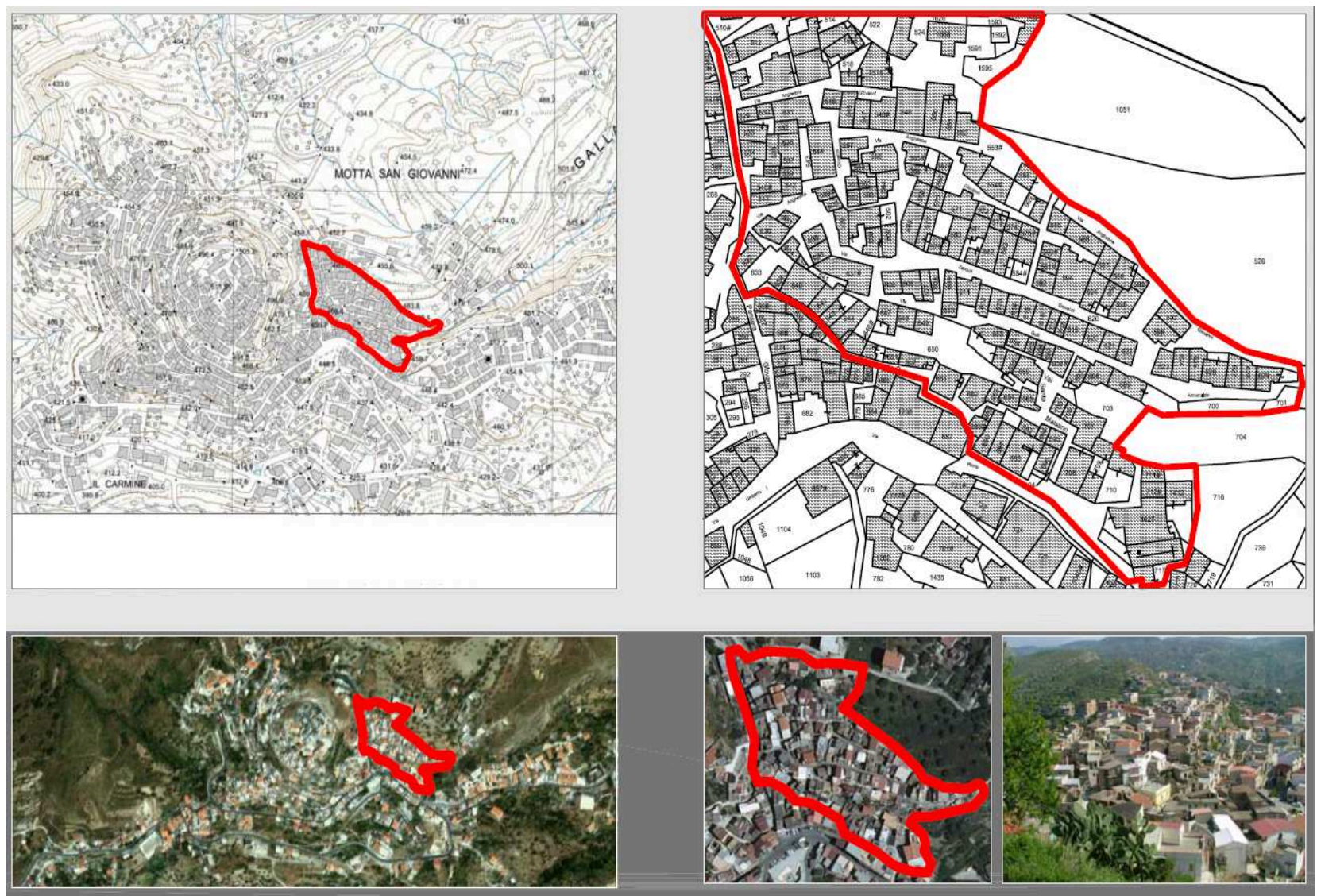

Fig. 1 - Motta San Giovanni, historical center
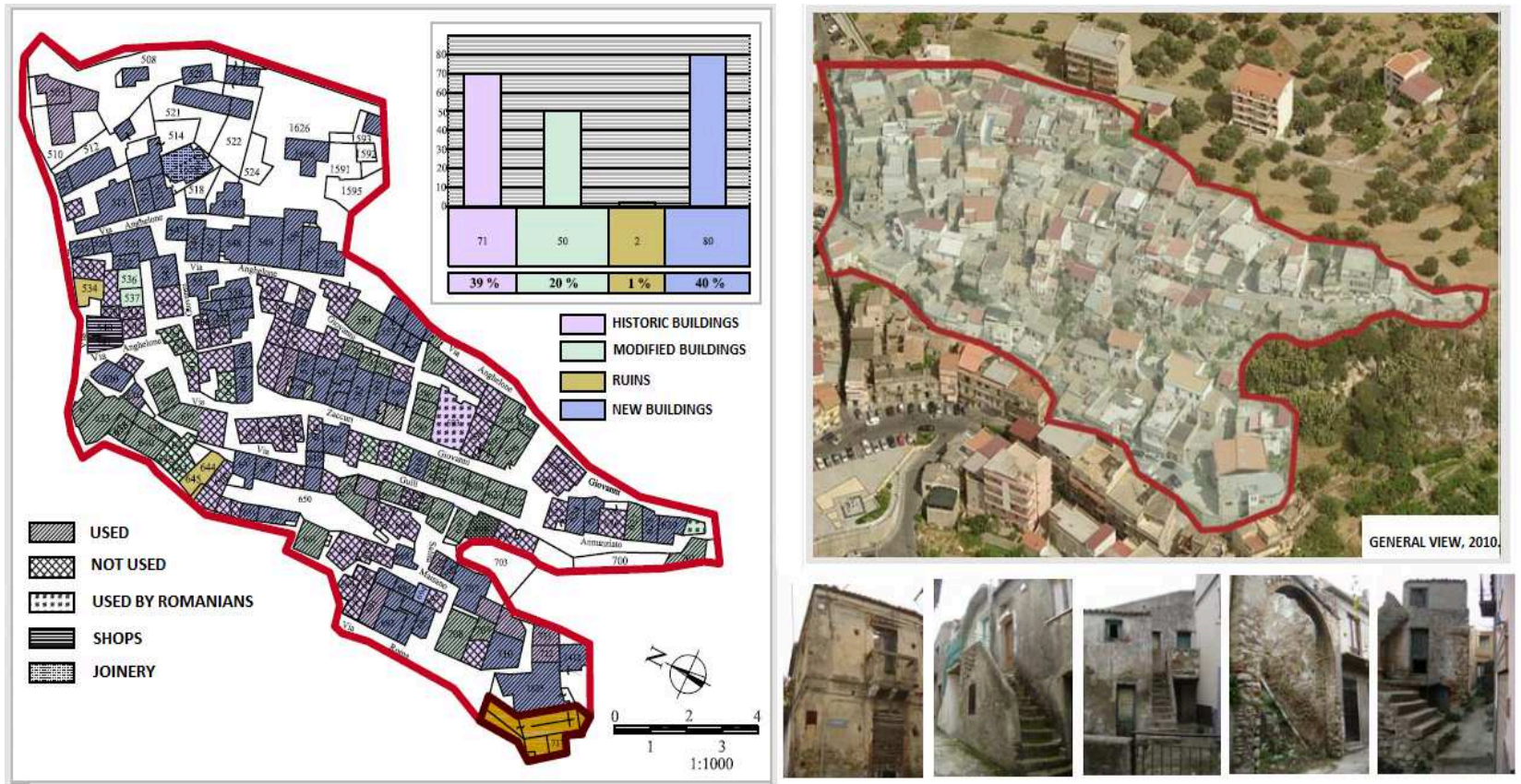

Fig. 2 - Localization of historical buildings in the actual content, use and conservative level 
This element produced on vernacular architectonic heritage of this village a phenomenon that alternates ruined or abandoned buildings to new construction, built in place of old houses, determining an architectonic expressive vocabulary strongly conflicting with the traditional architectures (Fig. 2), with three kinds of consequences: 1) in terms of urban qualification, the village runs the high risk of losing that sense of coherence, homogeneity and afflatus, that is one of main character of vernacular architecture in historical vernacular centers [5], 2) in architectural terms, it means to loss an interesting heritage, which is result of many centuries of history and tradition [6]; 3) in social terms, this produces a marginalization of migrant communities, relegated at the margins of urban areas [7], penalizing their ability to be part of the progress of the whole community [8].
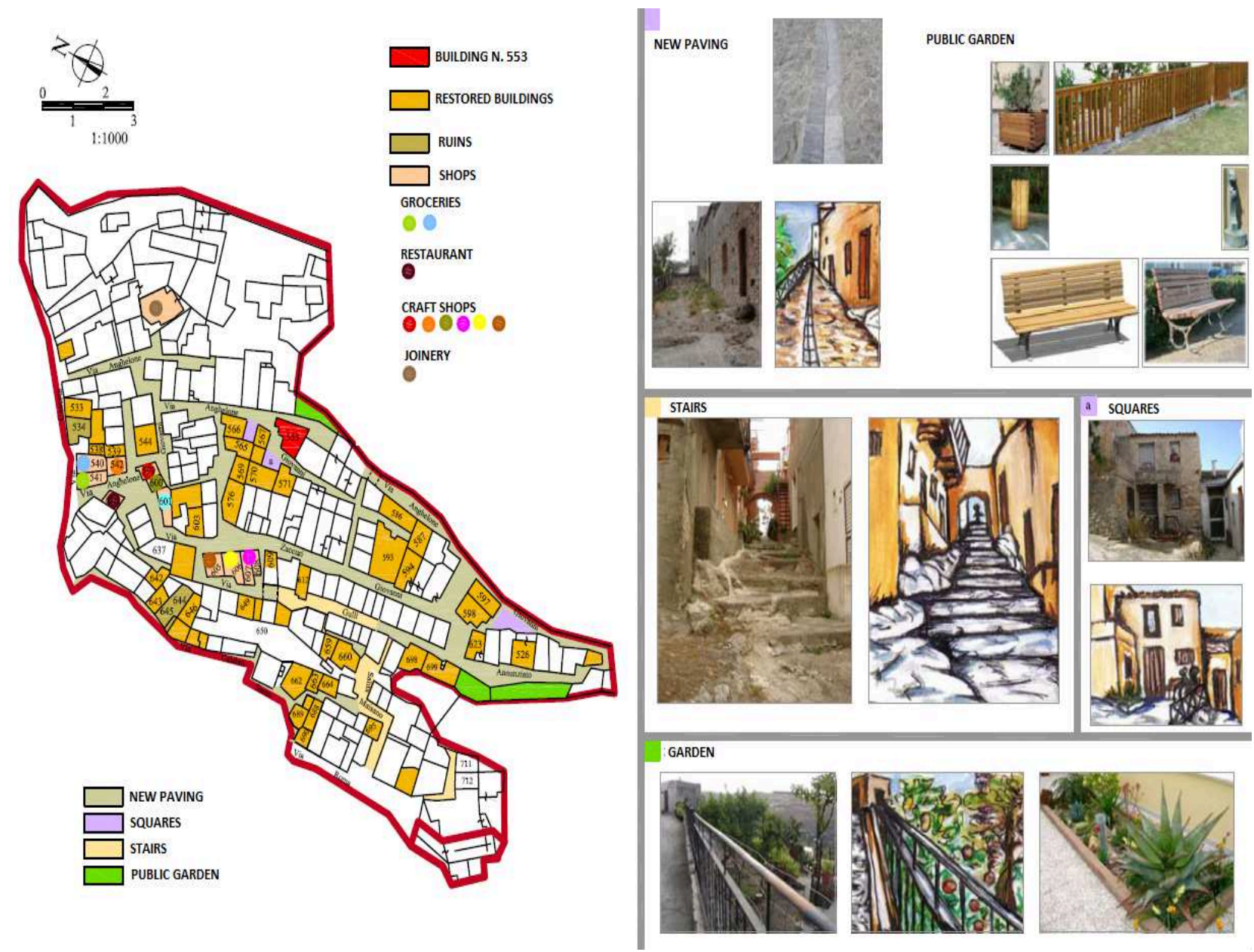

Fig. 3 - Localization of historical houses and reuse proposal as stores and houses for the Romunian comunity in Motta San Giovanni

For this reasons, the research suggests for Motta San Giovanni village a restoration and conservation plan, aimed:

1) to discourage the demolition-reconstruction process and encourage a sustainable conservation and preservation;

2) to make this places appropriate also to the needs of Romanian community, for example restoring one of its abandoned Catholic church to reuse it as Romanian rite church;

3 ) to support an equalization process, where the Municipality gives Romanian community some ancient houses, requiring them to realize their restoration in according to conservation criteria;

4) to support the Romanian community, favoring a self-made restoration, considering that Romanians are widely work in construction industry, with the possibility to experience specializing in restoration, starting from their home. 

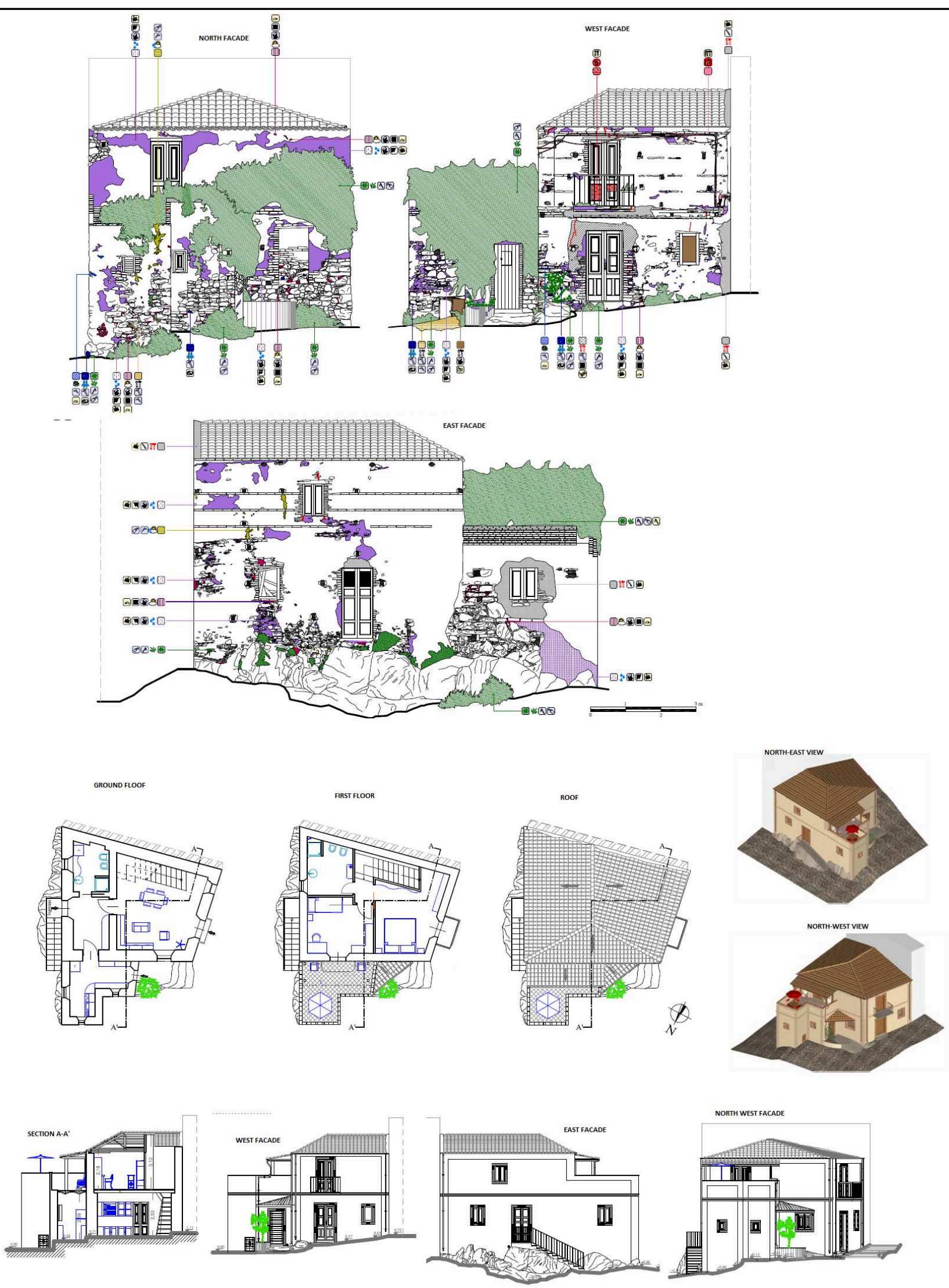

Fig. 4 - House n. 553, The proposal: preservation, retrofitting and adaptive reuse 
For suggesting a pragmatic example of how to obtain these results, the research proposes a detailed restoration project for an applicative case, the building n. 553 (Fig. 4), on which a set of guidelines [9] for interventions of restoration and conservation are applied, in terms of technical-constructive and seismic requalification, in agreement with the new laws and in order to propose environmental sustainability strategy, also in terms of building performance characteristics during its entire life cycle. The conservation of architectural heritage is, in fact, encouraged by the ability to provide functions useful for the society and, in this way, to preserve the historic building also means adapting the building to the needs of contemporary life, without compromising the identity values. Maintaining respect for both requests, is difficult and often impossible, and due to this the building ends up being abandoned, and falling into disrepair as a result of the ravages of time and non-use. However the ancient building, especially the vernacular one, already contains some technical solutions, which are different depending on the local context, able to optimize the living comfort.

\section{Conclusions}

This research therefore focuses on the cultural assumption that recovering and improving the quality of urban life, preserving the aesthetic and constructive values of ancient vernacular villages, is a useful strategy for evolution of a social quality, where multicultural integration is not only occasion of enrichment, but also a strategy to preserve elective affinities of a place, disproving reasons of a prevaricating and protectionist identity, that the history of these places proves anachronistic and unsuccessful.

\section{References}

[1] V. Triolo, Degree dissertation: Motta San Giovanni (Reggio Calabria-Italy). Conservation and reuse-2010/11. Mediterranea University of Reggio Calabria, Faculty of Architecture, S.C.B.A.A. Program, mentors: Prof. Arch. Vittorio Ceradini and PhD Alessia Bianco

[2] A. De Lorenzo: Le quattro motte esistenti presso Reggio di Calabria, Edizioni Bernardino, Siena (1891)

[4] G. Caridi: Dal Feudatario ai Notabili. Il principato di Motta San Giovanni dal seicento agli inizi dell'Ottocento, Reggio Calabria, Falzea Editore (1996)

[3] F. Arillotta: La storia della Motta San Giovanni e del suo territorio, Reggio Calabria, Grafica Enotria (1999)

[5] M.C. Brandi: Le migrazioni qualificate dall'Europa dell'Est verso l'Italia, Centro studi emigrazione, Roma (2010)

[6] V. Rosato: Accoglienza e inserimento dei migranti, Centro studi emigrazione, Roma (2011)

[7] G. Carosso: Contrappunti in emigrazione, Elledici, Rivoli, (2011)

[8] M. Callari: Contesti urbani, processi migratori e giovani migranti, Guaraldi, Rimini (1999)

[9] V. Ceradini (edited by): Area Grecanica-Codice di Pratica per la sicurezza e la conservazione degli insediamenti storici, Gangemi Editore, Quaderni Del Dipartimento PAU, Anno XII 23-24 Roma (2003) 